\title{
Pendidikan Anti Korupsi Dalam Budaya Jawa
}

\author{
Daud Eliezar \\ desinaga@bps.go.id \\ Pusdiklat BPS, Jl. Raya Jagakarsa No. 70 \\ Anti-Corruption Education in Javanese Culture
}

\begin{abstract}
Anti-corruption is the most important part of solving the problem of corruption in Indonesia. Measuring the dimensions of the Anti Corruption Behavior Index (IPAK) shows an interesting phenomenon that is the understanding and assessment of the society tends to be more anti-corruption idealists, on the contrary in practice level when dealing with public services still perform corrupt behavior. Such a public service needs to be found a solution with a sociocultural approach, namely by implementing Javanese cultural values or expressions that are in line with the values contained in the anti-corruption values. Thus the noble values in Javanese culture can make corruption behavior be eliminated. Javanese culture can influence other cultures in carrying out anti-corruption values, where the population distribution is evenly distributed in all provinces in Indonesia. In the end, anti-corruption will become the culture of the Indonesian nation so that it can realize the goals of the Unitary Republic of Indonesia.
\end{abstract}

Keywords: Anti-Corruption, IPAK, Javanese Culture

\section{Article Info}

Received date: 27 Agustus 2019 Revised date: 10 Desember 2019 Accepted date: 22 Januari 2020

\section{PENDAHULUAN}

Bagi bangsa Indonesia, anti korupsi merupakan bagian terpenting dari pemecahan masalah korupsi di Indonesia. Korupsi harus dicegah dan diberantas demi mengembalikan tatanan nilai bangsa Indonesia kembali ke jalan yang benar. Tingkat korupsi yang tinggi dapat mengakibatkan pembangunan ekonomi berkelanjutan di Indonesia menjadi terhambat, contohnya pendapatan menjadi timpang.

Ketimpangan pendapatan suatu negara dapat dilihat dengan gini rasio, semakin besar angka gini rasio semakin timpang pendapatan antara yang berpendapatan tinggi dengan yang rendah.Tahun 2013 Indonesia menurut data Badan Pusat Statistik (BPS) gini rasionya adalah sebesar 0,413, hal ini menunjukkan bahwa ketimpangan pendapatan di Indonesia berada di tingkat ketimpangan sebesar 0,413 meningkat dibandingkan tahun sebelumnya yaitu sebesar 0,41 . Peningkatan gini ratio sebesar 0,003 menunjukkan bahwa ketimpangan pendapatan semakin lebar dengan kata lain pendapatan cenderung semakin tidak merata.

Organisasi transparancy international telah mempublikasikan nilai tentang Corruption Perceptions Index negara-negara di Asia Pasifik dari tahun 2012 sampai dengan 2016. Dari nilai indeks persepsi korupsi negara Indonesia dari tahun ke tahun semakin meningkat, hal ini menunjukkan upaya pemerintah dalam memberantas korupsi di Indonesia namun nilainya hanya 37 (tiga puluh tujuh) dari skala 100. Hal ini dapat berakibat pada kepercayaan investor dalam menanamkan modal di Indonesia menjadi lebih rendah.

BPS melaksanakan Survei Perilaku Anti Korupsi (SPAK) dan menghasilkan Indeks Perilaku Anti Korupsi (IPAK) yang menggambarkan dinamika perilaku anti korupsi masyarakat Indonesia. 


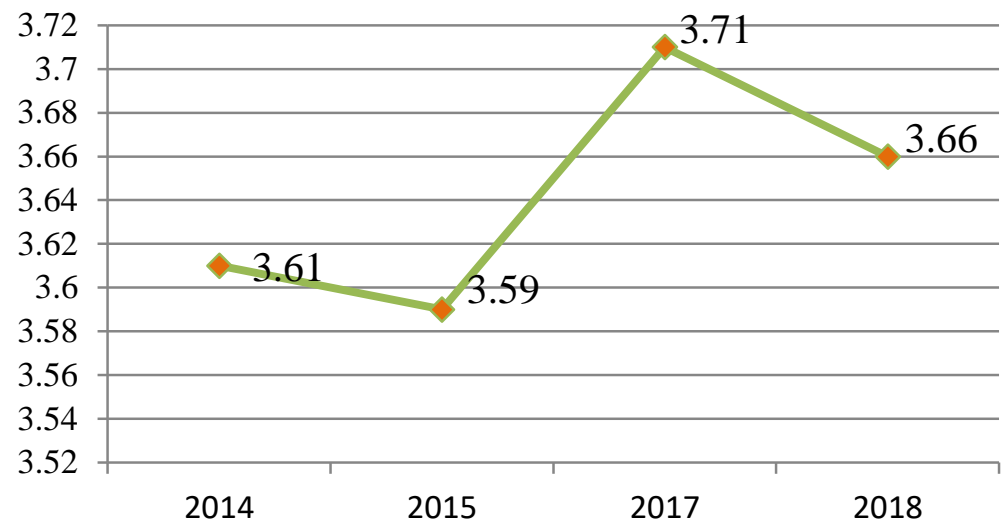

\section{Gambar 1.Grafik Indeks Perilaku Anti Korupsi Tahun 2014-2018}

Indeks Perilaku Anti Korupsi pada gambar di atas menunjukkan penurunan dari tahun 2017 ke 2018, hal ini menunjukkan bahwa kecenderungan pandangan masyarakat terhadap kebiasaan di masyarakat dan pengalaman berhubungan dengan pelayanan publik dalam hal perilaku korupsi meningkat.

Kecenderungan penurunan IPAK dapat dilihat dari dua dimensi utama, yakni pertama unsur persepsi yang berupa pendapat atau penilaian terhadap kebiasaan perilaku koruptif di masyarakat, dan yang kedua adalah pengalaman dalam berperilaku koruptif.

Tabel 2. Indeks PerilakuAnti Korupsi Menurut Dimensi Tahun 2012 - 2015

\begin{tabular}{lcccc}
\hline \multirow{2}{*}{ Dimensi } & \multicolumn{5}{c}{ Tahun } \\
\cline { 2 - 5 } & 2014 & 2015 & 2017 & 2018 \\
\hline Indeks Persepsi & 3,71 & 3,73 & 3,81 & 3,86 \\
\hline Indeks Pengalaman & 3,49 & 3,39 & 3,60 & 3,57 \\
\hline Sumber: Berita Resmi Statistik $B P S$ & &
\end{tabular}

Tabel 2 dari hasil pengukuran IPAK menurut dimensi, terlihat fenomena yang menarik untuk dicermati.Indeks dimensi persepsi menunjukkan tren yang cenderung meningkat dari tahun $2014 \mathrm{ke}$ 2018. Hal ini menggambarkan sisi pemahaman dan penilaian masyarakat cenderung semakin idealis anti korupsi. Sebaliknya dari dimensi pengalaman nilainya cenderung dibawah indeks persepsi. Keadaan demikian menggambarkan bahwa masyarakat dalam tataran praktek ketika berhadapan dengan pelayanan publik masih melakukan perilaku korupsi. Dengan kata lain, terkesan masyarakat semakin membenci korupsi (idealis) namun tidak sejalan dengan perilaku nyata dalam kehidupan sehari-hari.

Berdasarkan hal tersebut, maka diteliti nilai anti korupsi yang terkandung di dalam nilai-nilai luhur budaya. Transformasi budaya nusantara dihasilkan dari nilai-nilai adat yang terkandung pada suku. Suku di Indonesia yang memiliki jumlah penduduk paling banyak adalah suku Jawa. Penelitian terdahulu belum ditemukan yang meneliti tentang bagaimana nilai-nilai anti korupsi terkandung pada nilai-nilai budaya Jawa.

\section{KAJIAN PUSTAKA}

Keinginan korupsi dalam diri manusia merupakan hasil dari ketidaksesuaian antara perilaku dengan yang dipikirkan dan yang diucapkan serta hati nuraninya. Pendekatan strategi pemberantasan korupsi di lndonesia harus menggunakan 4 (empat) pendekatan yaitu, pendekatan hukum, pendekatan moralistik dan keimanan, pendekatan edukatif dan pendekatan sosiokultural (Romli Atmasasmita, 2002: 17).

Permasalahan tidak sejalannya perilaku nyata dalam kehidupan sehari-hari dengan idealisme masyarakat dalam membenci korupsi perlu dicarikan solusinya dengan pendekatan sosiokultural. Maka perlu diteliti bagaimana pemberantasan korupsi dengan pendekatan sosiokultural, yaitu membahas tentang nilai anti korupsi dalam masyarakat dilihat dari kearifan budaya Jawa. 
Hal ini sejalan dengan startegi pemberantasan korupsi melalui penguatan sosial kontrol yang kontruktif dan berdaya guna (Faisal Santiago, 2014: 67) dan pendidikan nilai budaya yang efektif melalui membiasakan bertingkah laku, pemberian contoh dan penciptaan suasana harmonis (Naniek Sulistya Wardani, 2015: 22) membuktikan adanya keterkaitan antara korupsi dengan mentalitas kebudayaan bahwa korupsi dapat diberantas dan dicegah dengan pendekatan kebudayaan (Listiyono Santoso dan Dewi Meyrasyawati, 2015: 43).

\section{METODE PENELITIAN}

Penelitian ini menggunakan pendekatan yang menekankan pada pembangunan naratif atau deskripsi tekstual atas fenomena yang diteliti. Khususnya menggunakan metode penelitian kepustakaan,berdasarkan pendapat Mestika Zed maka ada empat ciri utama studi pustaka, bahwa peneliti berhadapan langsung dengan teks (naskah) atau data angka dan bukan dengan pengetahuan langsung dari lapangan atau saksi mata berupa kejadian, orang atau benda-benda lainnya. Data pustaka bersifat siap pakai artinya peneliti tidak pergi kemana-mana kecuali hanya berhadapan langsung dengan bahan sumber yang sudah tersedia diperpustakaan, data pustaka umumnya adalah sumber sekunder artinya bahwa peneliti memperoleh bahan dari tangan kedua dan bukan data orisinil dari tangan pertama dilapangan, dan kondisi data pustaka tidak dibatasi oleh ruang dan waktu (Mestika Zed, 2004: 4-5).

Menurut Muri Yusuf variabel dapat diartikan bermacam-macam. Aspek yang akan menjadi pengamatan penelitian dapat diartikan sebagai suatu variabel (Muri Yusuf, 2014: 25).

Berdasarkan pendapat di atas maka variabel penelitian adalah suatu gejala yang menjadi objek atau perhatian dalam sebuah penelitian.Variabel yang digunakan dalam penelitian ini adalah variabel anti-korupsi dan budaya Jawa.

\section{HASIL PENELITIAN DAN PEMBAHASAN}

Tulisan ini meneliti tentang nilai-nilai anti korupsi yang terkandung pada nilai-nilai budaya di Indonesia.Adapun nilai-nilai anti korupsi menurut modul Anti Korupsi Pelatihan Dasar Calon Pegawai Negeri Sipil (CPNS) Golongan III adalah jujur, peduli, mandiri, disiplin, tanggungjawab, kerja keras, sederhana, berani dan adil. Sub bagian membahas nilai anti korupsi terkandung di dalam budaya sukusuku di Indonesia dan sebarannya.

\section{Nilai-Nilai Anti Korupsi di Dalam Budaya Jawa}

Budaya yang merupakan karakter, perilaku, ungkapan-ungkapan, falsafah maupun arti dari bangunan bersejarah dimiliki oleh budaya Jawa yang mengandung unsur nilai-nilai anti korupsi, di antaranya:

\section{Jujur}

Nilai kejujuran merupakan salah satu nilai anti korupsi yang dapat dilihat kandungannya di dalam budaya Jawa dibawah ini, yaitu:

Budaya Suku Jawamemiliki budaya kejujuran seperti yang disampaikan oleh Wandansari dalam tulisannya yang berjudul Aktulialisasi Nilai-Nilai Tradisi Budaya Daerah Sebagai Kearifan Lokal Untuk Memantapkan Jatidiri Bangsa, sebagai berikut:

"Manusia Jawa diajarkan untuk selalu bersikap prasaja, sikap jujur yang didasari pada keberlangsungan tatanan."

Dari tulisan di atas dimaknai bahwa budaya suku Jawa mengutamakan keselarasan batin, melalui sikap jujur dalam menjalani kehidupan ini baik dalam hubungn dengan manusia terutama dengan Tuhan.

\section{Peduli}

Nilai anti korupsi peduli, kandungannya terdapat pada budaya suku Jawa seperti yang disampaikan oleh Wandansari dalam tulisannya yang berjudul Aktulialisasi Nilai-Nilai Tradisi Budaya Daerah Sebagai Kearifan Lokal Untuk Memantapkan Jatidiri Bangsa, seperti yang tertulis dibawah ini: 
"Sikap batin dalam menjaga keselarasan interaksi sosial, selalu dijaga dalam parameter yang bersifat ajeg, tidak ada gejolak, selalu mengedepankan kedamaian atau lebih dikenal dengan harmoni sosial. Hal itu dapat berjalan karena manusia Jawa merasa bahwa individu dengan segala kepentingannya merupakan bagian integral dari sebuah komunitas."

Budaya suku Jawa mengedepankan kedamaian dengan sesama dan alam lingkungannya, melalui kepedulian dari dalam hati untuk saling memahami kebutuhan sehingga menimbulkan keharmonisan di kehidupan manusia bersama alamnya.

\section{Mandiri}

Budaya Suku Jawa, nilai mandiri disampaikan dalam tulisannya yang berjudul Aktulialisasi Nilai-Nilai Tradisi Budaya Daerah Sebagai Kearifan Lokal Untuk Memantapkan Jatidiri Bangsa oleh Wandansari berikut kutipannya:

"Pada bangunan keraton Gapura Pamurakan, dahulu digunakan untuk membagi hewan buruan dimana jumlah yang diterima tidak sama. maknanya adalah narima ing pandum (menerima akan rejeki dari Tuhan seberapapun besarnya).

Bentuk bangunan Semar tinandhu, Mandung = berhenti. Secara lahir untuk menata diri sebelum masuk keraton, maknanya: mawas diri/berkaca, melihat kekurangan diri sendiri sebelum melihat kekurangan orang lain.”

Dimaknai bahwa dengan berserah penuh kepada Tuhan memperkuat kemandirian dalam menjalani kehidupan dengan menata diri melalui mawas diri atau selalu mengoreksi diri sendiri, karena diyakini bahwa semua datang dari Tuhan dan manusia hanya menjalankan kehendakNya.

\section{Disiplin}

Budaya Suku Jawa mempunyai budaya disiplin sesuai dengan yang ditulis oleh Wandansari.berjudul Aktulialisasi Nilai-Nilai Tradisi Budaya Daerah Sebagai Kearifan Lokal Untuk Memantapkan Jatidiri Bangsa. Berikut ini adalah bagian dari tulisan tersebut:

"Serat Sastra Gendhing, banyak diungkap tentang kapabilitas raja / pemimpin dalam membentuk karakter masyarakatnya. Raja / pemimpin harus terlebih dahulu dapat memposisikan dirinya sebagai panutan."

Orang-orang suku Jawa mengkondisikan dirinya menjadi seorang yng selalu menjaga kedisiplinan terutama untuk membentuk sosok pemimpin yang selalu ditiru tingkah lakunya dan disiplin dalam perbuatan baik.

\section{Tanggungjawab}

Budaya Suku Jawa, nilai tanggungjawab terkandung dalam budaya suku Jawa diungkapkan di dalam tulisan yang berjudul Alam Pikiran dalam Masyarakat Budaya Jawa yang ditulis oleh Sutiyono, seperti yang tertulis dibawah ini:

"Wedhatama Winardi disebutkan: Sejatine kang mangkana/wus kakenan nugrahaning Hyang Widhi/bali alaming asuwung/tan karem karameyan/ingkang sipat winisesa wus/mulih mulamulanira/mulane wong anom sami (Bilamana orang sudah sampai pada tingkatan/alam yang demikian, maka itulah tandanya kalau rasanya telah manunggal dengan Yang Maha esa. Artinya telah mendapatkan anugerah Tuhan-kembali ke alam kosong-hampa, sehingga padamlah segala luapan hawa nafsunya, jernihlah budinya, istirahatlah panca inderanya dan tentramlah lahir batinnya, terlepas dari segala keinginan loba-tamanya, kembali ke asal mulanya)."

Makna yang terkandung didalam kutipan tulisan di atas adalah sebagai manusia Jawa selalu bertanggung jawab dengan Sang Pencipa, ditunjukkan dengan cara menahan hawa nafsu, jernih dalam berpikir dan menenteramkan lahir dan bathinnya sebagai bukti penyatuan diri bersama Tuhan. 


\section{Kerja Keras}

Budaya Suku Jawa terkandung nilai kerja keras seperti yang ditulis oleh Wandansari yang berjudul Aktulialisasi Nilai-Nilai Tradisi Budaya Daerah Sebagai Kearifan Lokal Untuk Memantapkan Jatidiri Bangsa, berikut ini adalah kutipannya:

"Mamasuh malaning bumi, merupakan sikap pro aktif dalam menjaga harmoni/keselarasan bumi yang sudah terinteraksi elemen satu dengan yang lainnya"

Makna yang terkandung adalah seorang Jawa selalu menjaga keharmonisan di bumi baik dengan lingkungan maupun sesama manusia dengan selalu bekerja keras dalam mencapainya.

\section{Sederhana}

Budaya Suku Jawa mengandung nilai sederhana seperti diungkapkan oleh Sutiyono di dalam tulisan yang berjudul Alam Pikiran dalam Masyarakat Budaya Jawa, seperti yang terkutip pada tulisan berikut ini:

"Serat Kaca Wirangi (1922: 22) sebagai berikut: manungsa kang sampurna ora ngatonake kaananing dhirine, katanding lan kaananing dhiri liyane. Kahananing sakehing dhiri kabeh, rinasa sipating pribadine. Rehne ala lan becikepinendhem, dadi mung ngatonake kahananing dhiri liya, kaanggep padha lan dhirine, kabeh rinasa sipate pribadi. Intinya bahwa orang yang telah mencapai hidup sempurna itu tidak memperlihatkan diri, tidak terlihat kepintarannya, kemampuannya, dan kelebihannya, dan lebih memperlihatkan dirinya dengan orang lain itu sama derajatnya, atau bahkan di bawahnya."

Dari kutipan tullisan di atas bermakna bahwa manusia bersuku Jawa dalam menjalani hidupnya selalu menjunjung tinggi nilai kesederhanaan dengan cara tidak memperlihatkan kemampuan, kelebihan, kepintaran dan dirinya dengan kata lain bersikap rendah hati.

\section{Berani}

Budaya Suku Jawa, nilai berani terkandung di dalam budaya suku Jawa seperti terdapat dalam tulisan yang berjudul Aktulialisasi Nilai-Nilai Tradisi Budaya Daerah Sebagai Kearifan Lokal Untuk Memantapkan Jatidiri Bangsa ditulis oleh Dra. GKR. Wandansari, M.Pd., berikut ini adalah kutipannya:

"Pohon beringin di Keraton, merupakan lambang kejayaan seorang raja. Juga bermakna pengayoman, keadilan dan kewibawaan."

Maknanya bahwa seorang suku Jawa memiliki nilai keberanian dalam mengayomi dan berani memperjuangkan keadilan sehingga akan memunculkan kewibawaan di dalam dirinya.

\section{Adil}

Budaya Suku Jawa terdapat dalam tulisan yang berjudul Aktulialisasi Nilai-Nilai Tradisi Budaya Daerah Sebagai Kearifan Lokal Untuk Memantapkan Jatidiri Bangsa ditulis oleh Dra.GKR. Wandansari, M.Pd., nilai adil terkandung dalam bagian dari tulisan berikut:

"Serat Sastra Gendhing, salah satu karya sastra masa Sultan Agung, menciptakan angger-angger yang sarat dengan tuntunan sikap hidup, ajaran untuk menjadi pemimpin yang baik, pemimpin yang mempunyai ketegasan dan tidak bersikap ragu serta adil sehingga dapat menciptakan negara yang tata tentrem kerta raharja."

Seorang manusia bersuku Jawa memiliki keinginan mewujudkan negara yang damai, adil dan makmur dengan cara memimpin yang baik dan tegas dalam memperjuangkan keadilan.

\section{Sebaran Suku-Suku di Indonesia}

Indonesia sebagai negara yang heterogen mempunyai beraneka ragam suku yang tersebar di seluruh wilayah membawa nilai-nilai budaya, agama, dan adat istiadat (tradisi) masing-masing. 
Dari sebaran suku-suku di seluruh Indonesia, suku asli dari provinsi masing-masing masih mendominasi dari suku-suku lainnya kecuali di provinsi Lampung dan Kalimantan Timur. Yang menarik adalah ada suku yang tersebar diseluruh provinsi di Indonesia dari mulai wilayah Sumatera sampai dengan kawasan timur di Indonesia yaitu suku Jawa. dengan kata lain budaya yang dibawa dari orang-orang suku Jawa yang mengandung budaya anti korupsi di dalam budaya suku Jawa juga terdapat di seluruh daerah di Indonesia dan tentunya dapat dirasakan oleh suku-suku asli daerah provinsi tersebut maupun suku yang lainnya dalam pergaulan sehari-hari baik di lingkungan rumah maupun di kantor.

\section{SIMPULAN DAN SARAN}

Pendidikan anti korupsi berupa nilai-nilai anti korupsi diantaranya nilai kejujuran, kepedulian, mandiri, disiplin, tanggung jawab, kerja keras, sederhana, berani dan nilai keadilan terbukti terkandung di dalam budaya Jawa. Indonesia dilihat dari suku-suku yang mendiami di berbagai pulau selain suku asli pulau tersebut juga terdapat suku-suku yang lainnya.Terdapat suku-suku yang secara jumlah lebih besar dibandingkan dengan suku-suku yang lainnya dan membawa perilaku dan budayanya masingmasing berupa nilai-nilai atau ungkapan-ungkapan yang sejalan dengan nilai-nilai yang terdapat didalamnya nilai anti korupsi. Dengan melaksanakan nilai-nilai luhur pada budaya yang dimiliki oleh suku Jawa dapat membuat perilaku korupsi yang ada pada manusia Indonesia bisa dihilangkan.

Pendidikan anti korupsi dapat langsung diterapkan oleh orang-orang yang menganut budaya Jawa yang berupa karakter, bangunan maupun ungkapan-ungkapan terkandung. Budaya suku Jawa yang tersebar di seluruh Indonesia dapat mempengaruhi budaya suku yang lainnya dalam menjalankan nilai anti korupsi. Dengan mempelajari budaya suku Jawa otomatis sudah mendapat pendidikan anti korupsi. Penerapan budaya Jawa dalam kehidupan dan pergaulan sehari-hari baik di lingkungan rumah maupun kantor selaras dengan nilai anti korupsi sehingga nilai-nilai anti korupsi akan menjadi budaya bangsa Indonesia yang tentunya tujuan Negara Kesatuan Republik Indonesia dapat terwujud.

\section{UCAPAN TERIMA KASIH}

Ucapan terima kasih dipersembahkan pada seluruh teman-teman seprofesi Widyaiswara yang selalu meluangkan waktunya bersedia berdiskusi dalam menyempurnakan tulisan ini. Pada akhirnya ucapan terima kasih juga diucapkan untuk seluruh pegawai Pusdiklat BPS beserta dengan jajaran pimpinannya.

\section{DAFTAR PUSTAKA}

Abdallah K, K., \& Parama P, P. (2016). Kearifan Lokal Sebagai Benteng Karakter Bangsa. ETNOGRAFI, 1-58.

Atmasasmita, R. (2002). Strategi Pemberantasan Korupsi di Indonesia. Wacana Paramarta Edisi I Nomor I.

Badan Pusat Statistik. 2018. Berita Resmi Statistik: Indeks Perilaku Anti Korupsi (IPAK) 2018, Jakarta.

Diansyah, F. (2009). Senjakala Pemberantasan Korupsi; Memangkas Akar Korupsi dari Pengadilan Tipikor. Jurnal Konstitusi, Juli, 6(2), 7-42.

Dikdik, B. A.. 2009. Wawasan Tentang Manusia Dan Masyarakat Dalam Perspektif Kebudayaan. 21 Juli 2017. https://baehaqiarif.files.wordpress.com/20019/

Dokhi, M., Siagian, T. H., Sukim, Wulansari, I. Y., Hadi, D. W., \& Sambodo, N. 2016. Analisis Kearifan Lokal Ditinjau dari Keragaman Budaya Tahun 2016. Jakarta: Pusat Data dan Statistik Pendidikan dan Kebudayaan (PDSPK).

Kartono Kartini, 1980. Pengantar Metodologi Research Sosial. Alumni: Bandung.

Lembaga Administrasi Negara, 2015. Modul Diklat Prajabatan Golongan III Mata Diklat Anti Korupsi. Jakarta, 2015.

Marsi Singarimbun dan Sofian Effendi, 1989. Metode Penelitian Survei. LP3ES: Jakarta. 
Muhlizi, A. F. (2014). Membangkitkan Budaya Nusantara Yang Anti Korupsi. dalam Jurnal RechtsVinding Online: Media Pembinaan Hukum Nasional, 1(1).

Nawawi Hadari, 1983. Metode Penelitian Bidang Sosial. Gajah Mada University Press: Yogyakarta.

Prayitno, U. S. 2013. Kontekstualisasi Kearifan Lokal Dalam Pemberdayaan Masyarakat. Jakarta: Pusat Pengkajian, Pengolahan Data dan Informasi (P3DI) Setjen DPR Republik Indonesia dan Azza Grafika.

Sanusi, H.M. Arsyad, (2009). Relasi Antara Korupsi dan Kekuasaan. Jurnal Konstitusi Volume 6, Nomor 2, 83-104.

Santiago, F. (2014, January). Strategi Pemberantasan Tindak Pidana Korupsi Kajian Legal Sosiologis. Forum Pimpinan Pendidikan Tinggi Hukum Indonesia (FPPTHI).

Santoso, L., \& Meyrasyawati, D. (2015). Model Strategi Kebudayaan dalam Pemberantasan Korupsi di Indonesia. Jurnal Review Politik, 5(01), 22-45.

Setyawan, I. (2015). Faktor-Faktor Penyebab Tindak Pidana Korupsi Meningkat Di Indonesia. Jurnal Kultura, Volume: 16 No. 1, 5210-5216.

Subagyo Joko, 2006. Metode Penelitian (dalam Teori dan Praktek). Rineka Cipta: Jakarta.

Sudaryat, Y. 2015, Januari 8. Makalah. Retrieved Februari 14, 2018, from Universitas Negeri Jakarta: http://ikadbudi.uny.ac.id/sites/ikadbudi.uny.ac.id/files/lampiran/MAKALAH_0.pdf

Sutiyono. (n.d.). Staf. Retrieved Oktober 22, 2015, from Universitas Negeri Yogyakarta: http://staffnew.uny.ac.id/upload/131808675/penelitian/WUNY-Alam+Pikiran+Jawa.pdf

Wandansari, G. 2015, Januari 8. Makalahi. Retrieved Februari 14, 2018, from Universitas Negeri Yogyakarta:http://ikadbudi.uny.ac.id/sites/ikadbudi.uny.ac.id/files/lampiran/MAKALAH_0.p df

Wardani, N. S. (2015). Pengembangan Nilai-Nilai Budaya Sekolah Berkarakter. Scholaria: Jurnal Pendidikan Dan Kebudayaan, 5(3), 12-22.

Wicaksono, K. W. (2008). Penguatan Modal Sosial: Sebuah Jalan Keluar Menyelesaikan Korupsi Di Indonesia. Jurnal Ilmiah Niagara Vol. 1 No. 2, 35-49.

Yusuf Muri, 2014. Metodologi Penelitian Kuantitatif, Kualitatif dan Penelitian Gabungan. PT. Fajar Interpratama Mandiri: Jakarta.

Zed, Mestika, 2004. "Metode Penelitian Kepustakaan”. Yayasan Obor Indonesia, Jakarta, 2004. 